\title{
PRODUÇÃO DE FORRAGEM E PERFILHAMENTO EM PASTOS DE CAPIM TANZÂNIA-1 ADUBADOS COM DOSES DE NITROGÊNIO
}

\author{
HERBAGE PRODUCTION AND TILLERING IN TANZANIA GRASS \\ PASTURES FERTILIZED WITH NITROGEN DOSES
}

\author{
André Ricardo $\mathrm{HOESCHL}^{1}$ \\ Marcos Weber do CANTO ${ }^{2}$ \\ Amadeu Bona $\mathrm{FILHO}^{3}$ \\ Aníbal MORAES ${ }^{4}$
}

\begin{abstract}
RESUMO
O experimento de pastejo foi conduzido na Fazenda Nossa Senhora Aparecida, situada no município de Astorga, região Noroeste do Paraná, Brasil. O experimento visou avaliar quatro doses de nitrogênio (N) aplicadas ao solo de pastagens de capim Tanzânia-1 (Panicum maximum Jacq.). As doses avaliadas de $\mathrm{N}$ foram 100, 200, 300 e $400 \mathrm{~kg} \mathrm{ha}^{-1}$ e o delineamento experimental utilizado foi o inteiramente casualizado com duas repetições. O período experimental foi de 10/11/2001 a 15/04/2002. Os animais usados foram machos inteiros da raça Nelore e o método de pastejo empregado foi o de lotação contínua e taxa de lotação variável. $\mathrm{A}$ altura do pasto foi mantida o mais próximo possível de $60 \mathrm{~cm}$ em todas as unidades experimentais. A taxa de acúmulo de massa seca (MS) apresentou resposta linear positiva $(P<0,0112)$ com o aumento da quantidade de $\mathrm{N}$ aplicada. As taxas de acúmulo foram de 76 , 113, 138 e $152 \mathrm{~kg}$ de MS ha-1 dia-1, respectivamente para as doses de $\mathrm{N}$ de 100, 200, 300 e $400 \mathrm{~kg} \mathrm{ha}^{-1}$. A produção de forragem aumentou linearmente $(P<0,03)$ com o aumento da quantidade de $N$ aplicada. $A$ análise estatística revelou aumento linear $(P<0,05)$ da massa individual por perfilho com o aumento da dose de N. A densidade populacional de perfilhos vegetativos apresentou comportamento quadrático $(\mathrm{P}<0,003)$ com a elevação das doses de adubo nitrogenado.
\end{abstract}

Palavras-chave: adubação nitrogenada; capim Tanzânia; perfilhos.

\begin{abstract}
The present grazing experiment was carried in Nossa Senhora Aparecida Farm, located in the municipal district of Astorga, PR, Brazil. The experiment objectified to evaluate the effects of different amounts of applied nitrogen to the soil of Tanzania grass. The appraised doses of nitrogen were $100 \mathrm{~kg} \cdot \mathrm{ha}^{-1}, 200 \mathrm{~kg} \mathrm{ha}^{-1}, 300 \mathrm{~kg} \cdot \mathrm{ha}^{-1}$ and $400 \mathrm{~kg} \mathrm{ha}^{-1} \mathrm{of} \mathrm{N}$, and the completely randomized design was used with two replications. The experimental period was of November 10, 2001 to April 15, 2002. The used animals were young bulls Nelore. The put-and-take technique was used and the grazing method was of the continuous stocking. The height of the pasture was maintained about of $60 \mathrm{~cm}$ during the experimental period. The statistical analyses revealed lineal increase of the individual mass of the tillers with the amount of tested $\mathrm{N}$. The density tiller population presented behavior quadratic relationship the doses of $\mathrm{N}$. It is had as hypothesis that as if they elevate the levels of applied nitrogen, there will be an increase in the production of dry matter total and, due to the increase of the tillers density and production of heavier tillers.
\end{abstract}

Key-words: nitrogen fertilization; tanzânia grass; tillers.

\footnotetext{
${ }^{1}$ Zootecnista, Mestrando do Curso de Agronomia-Produção Vegetal da UFPR,Correspondente, Endereço: Rua Otacílio V. da Costa, 276, CEP 99501050, Lages-SC E-mail: decozoo@yahoo.com;

${ }^{2}$ Eng. Agrônomo,Professor Doutor do Depto. de Zootecnia da Universidade Estadual de Maringá.E-mail: canto@uem.br;

${ }^{3}$ Med.Veterinário,Professor Doutor do Depto de Agronomia da Universidade Federal do Paraná E-mail: bona@ufpr.br;

${ }^{4}$ Eng. Agrônomo,Professor Doutor do Depto de Agronomia da Universidade Federal do Paraná E-mail: anibalm@ufpr.br.
} 


\section{INTRODUÇÃO}

A produção animal por unidade de área das fazendas que criam bovinos de corte do Estado do Paraná é baixa. Nesse Estado a produção de bovinos de corte é realizada quase que exclusivamente em pastagens. Nos últimos anos estudos de pastejo (HOESCHL, 1999; CANTO et al., 2002; CANTO, 2003) realizados no Noroeste do Paraná mostraram que o cultivar Tanzânia-1 apresenta elevado potencial de produção animal.

A literatura é rica em trabalhos que mostram que pastos de Panicum maximum apresentam alta resposta à fertilização de $\mathrm{N}$ em termos de produção de forragem durante a estação de crescimento (MOTT et al., 1970; BOGDAN, 1977; CORSI e SANTOS, 1995; LUGÃO, 2001). De acordo com Humphreys (1991) aplicações de adubos nitrogenados em pastagens durante a estação de crescimento determinam melhorias na forragem disponível para o pastejo dos animais e isso se deve, principalmente, ao fato de os pastos se tornarem mais folhosos. De maneira geral essas melhorias na forragem disponível são expressas pela maior relação folha/colmo, pelo aumento na quantidade de lâminas de folhas verdes disponíveis e no teor de proteína bruta da forragem.

Trabalhos com plantas forrageiras (MAZZANTI et al., 1994; CRUZ e BOVAL, 1999; CANTO, 2003) demonstraram que distintas doses de $\mathrm{N}$ podem causar alterações em muitas das principais características da pastagem. Dentre essas, o índice de área foliar, a quantidade de massa de forragem, a massa de folhas verdes e a população de perfilhos. Variáveis descritoras do estado e das condições da pastagem podem influenciar a produção de forragem e a produção animal em pastagens (HODGSON, 1985).

O objetivo do presente experimento de pastejo foi avaliar o efeito de doses de N (100, 200, 300 e 400 $\mathrm{kg} \mathrm{ha-1}$ ) sobre a produção de forragem e o comportamento do perfilhamento de pastagens de capim Tanzânia. Assim, variáveis como a taxa de acúmulo de MS, a produção de forragem, a massa individual dos perfilhos, a densidade populacional de perfilhos basilares vegetativos e a densidade populacional de perfilhos aéreos foram avaliadas.

\section{METODOLOGIA}

O experimento de pastejo foi conduzido na Fazenda Nossa Senhora Aparecida, situada no Município de Astorga, $3^{\circ}$ Planalto Paranaense, região Noroeste do Paraná (51⒊ $39^{\prime \prime}$ de longitude, $23^{\circ} 39^{\prime \prime}$ de latitude e $542 \mathrm{~m}$ de altitude). O experimento foi realizado no período de 10 de novembro de 2001 a 15 de abril de 2002. O solo da área experimental é classificado como Latossolo Vermelho Distroférrico Argiloso (EMBRAPA, 1999). Os resultados médios da análise de solo estão descritos a seguir: $\mathrm{pH} \mathrm{CaCl}_{2}=5,4$; $\mathrm{Al}^{+3}=0,0 \mathrm{cmol} \mathrm{dm}^{-3} ; \mathrm{H}^{+}+\mathrm{Al}^{+3}=3,66 \mathrm{cmol} \mathrm{dm}^{-3} ; \mathrm{Ca}^{++}=7,7$ $\mathrm{cmol}_{\mathrm{c}} \mathrm{dm}^{-3} ; \mathrm{K}^{+}=0,63 \mathrm{cmol}_{\mathrm{c}} \mathrm{dm}^{-3} ; \mathrm{P}=8,4 \mathrm{mg} \mathrm{dm}^{-3} \mathrm{e}$ $\mathrm{C}=14,5 \mathrm{~g} \mathrm{dm}^{-3}$.
O delineamento experimental utilizado foi o inteiramente casualizado com duas repetições. Os tratamentos avaliados foram quatro doses de $\mathrm{N}(100$, 200,300 e de $400 \mathrm{~kg}$ de $\mathrm{N} \mathrm{ha}^{-1}$ ), aplicadas utilizandose o fertilizante nitrato de amônio $(33 \%$ de $N)$ foi o adubo nitrogenado utilizado. A área experimental possui oito unidades experimentais com aproximadamente um hectare. O método de pastejo empregado foi o de lotação contínua e taxa de lotação variável (MOTT e LUCAS, 1952), o que permitiu que os pastos fossem mantidos em alturas próximas de $60 \mathrm{~cm}$. A altura de pasto foi estimada por meio de 50 medidas realizadas semanalmente por unidade experimental, utilizando-se uma régua. Esta era posicionada em locais aleatórios do piquete A taxa de acúmulo de MS foi estimada a intervalos mensais por meio do uso de duas gaiolas de exclusão em cada unidade experimental. A taxa de acúmulo de MS foi estimada a intervalos mensais por meio do uso de duas gaiolas de exclusão do pastejo em cada unidade experimental. As gaiolas de exclusão do pastejo foram confeccionadas com estrutura de ferro de meia polegada de diâmetro e tela de malha $5 \mathrm{~cm}$. A base da gaiola mediu $1,96 \mathrm{~m}^{2}(1,4 \times 1,4 \mathrm{~m})$, o topo $(1,1 \mathrm{X}$ $1,1 \mathrm{~m})$ e a altura da gaiola de $1,8 \mathrm{~m}$. Um quadrado de ferro de $0,25 \mathrm{~m}^{2}$ de área foi usado para o corte da forragem dentro e fora da gaiola. A equação de Campbell (1966) permitiu o cálculo da taxa de acúmulo de MS. A produção de forragem foi obtida a partir da taxa de acúmulo de MS multiplicada pelo número de dias do período experimental.

Mensalmente foram coletados 50 perfilhos em cada unidade experimental para a estimativa da massa de perfilhos individuais. Os perfilhos foram cortados próximos ao nível do solo. Os perfilhos amostrados foram aqueles considerados representativos do tamanho médio da população de perfilhos no momento da amostragem. Após a coleta no campo, os perfilhos foram acondicionadas em sacos de papel e, enviadas para o Laboratório de Nutrição de Ruminantes do Departamento de Zootecnia da Universidade Estadual de Maringá, onde foram colocados em estufa de circulação forçada de ar por 56 horas. A estimativa da densidade populacional de perfilhos foi realizada utilizando-se um quadrado de ferro de $0,25 \mathrm{~m}^{2}(0,50 \mathrm{~m} \times 0,50 \mathrm{~m})$ de área em seis locais da unidade experimental. Os locais escolhidos foram aqueles considerados representativos da densidade média de perfilhos da pastagem no momento da amostragem. Os perfilhos foram classificados e contados conforme sua posição na planta (perfilho basilar ou aéreo) e quanto ao seu estádio (vegetativo ou reprodutivo). Dessa maneira foi possível estimar a densidade populacional de perfilhos basilares vegetativos, de perfilhos basilares reprodutivos e perfilhos aéreos vegetativos e reprodutivos. Foram considerados como perfilhos reprodutivos aqueles que apresentavam a inflorescência visível. As relações entre as variáveis foram analisadas por meio de equações de regressão, utilizando-se o programa computacional STATGRAPHICS. 
A relação entre a massa individual dos perfilhos com as doses de $\mathrm{N}$ pode ser vista na Figura 1. Houve aumento linear positivo $(P<0,05)$ da relação $M S$ de perfilho com as doses de $\mathrm{N}$ aplicadas. Pela equação de regressão da Figura 1 pode-se verificar que os valores de massa dos perfilhos foram de 2,23; 2,55; 2,71 e de $2,87 \mathrm{~g}$ de $\mathrm{MS}$ perfilho-1, respectivamente, para as doses de 100, 200, 300 e de 400 de kg ha-1.

Houve leve aumento nas alturas médias mantidas nos tratamentos das maiores doses de $\mathrm{N} \mathrm{e}$ isso possivelmente se refletiu na massa dos perfilhos. Um outro fator é que plantas de capim Tanzânia melhor nutridas em $\mathrm{N}$ apresentam maior vigor e, por vezes, aumento do número de folhas verdes na sua estrutura. No entanto, o resultado mostrado na Figura 1 contrasta com aquele verificado por CANTO (2003), onde não foi observada variação em massa dos perfilhos com as doses de $\mathrm{N}$ de zero, 200, 400 e 600 $\mathrm{kg} \mathrm{ha}^{-1}$ em pastagens de capim Tanzânia manejadas sob lotação contínua. Nesse último estudo de pastejo os valores de MS por perfilho foram inferiores aos observados no presente experimento. O perfilho é a unidade vegetativa básica das gramíneas (HODGSON, 1990) ,o que determina, por meio da sua densidade populacional,e de sua massa individual, a quantidade de massa de forragem presente instantaneamente acima do nível do solo na pastagem.

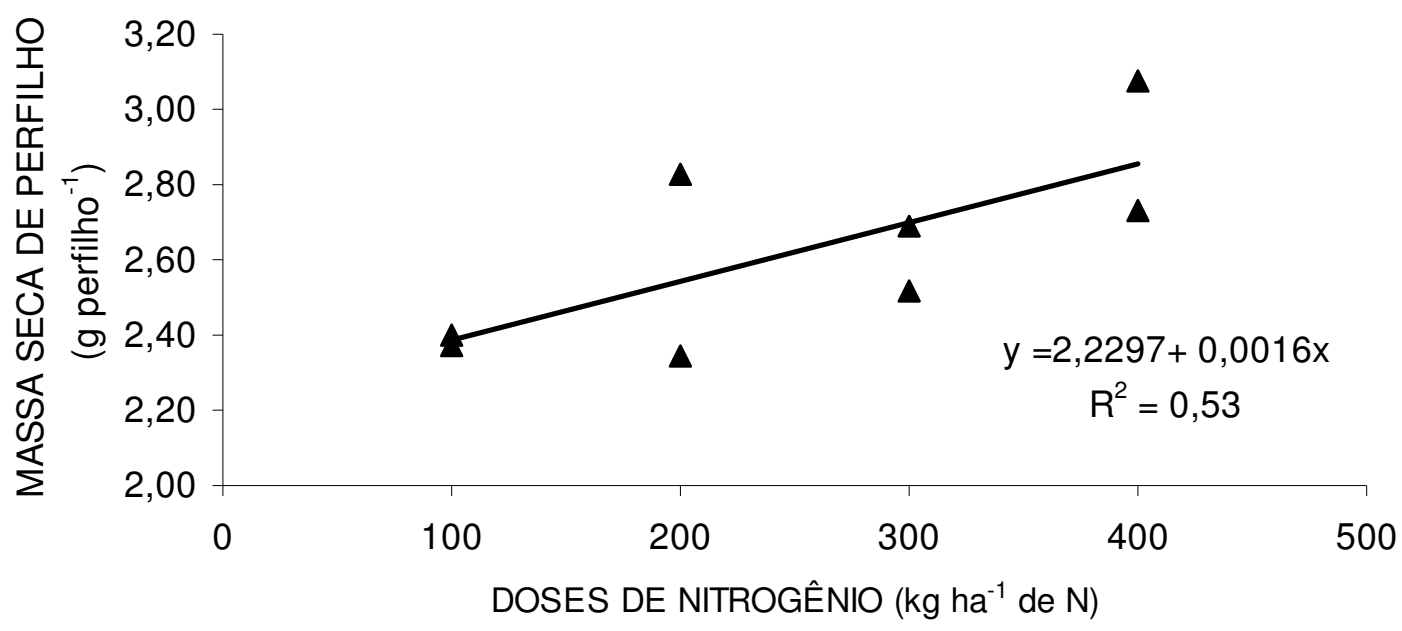

FIGURA 1 - Massa por perfilho em pastos de capim Tanzânia adubados com doses de nitrogênio - Astorga, PR, 2002.

$\mathrm{Na}$ Figura 2 pode ser analisada a relação quadrática $(P<0,003)$ entre as doses de $N$ e a densidade populacional de perfilhos basilares que se apresentavam no estádio vegetativo. As densidades populacionais médias calculadas de acordo com a equação de regressão da Figura 2 foram 655; 779; 767 e de 787 perfilhos $\mathrm{m}^{-2}$ para os tratamentos 100; 200; 300 e $400 \mathrm{~kg} \mathrm{ha}^{-1}$ de $\mathrm{N}$ respectivamente. O baixo valor do coeficiente de determinação $\left(R^{2}\right)$ da curva da Figura 1, deve-se principalmente a grande variação da massa dos perfilhos entre as repetições do tratamento $200 \mathrm{~kg} \mathrm{ha}^{-1}$ de $\mathrm{N}$, onde uma delas devido à característica do dossel, apresentou valores bem superiores aos esperados, ficando acima dos valores encontrados no tratamento $300 \mathrm{~kg} \mathrm{ha}^{-1}$ de $\mathrm{N}$.

Segundo LEMAIRE e CHAPMAN (1996), o efeito positivo do nitrogênio sobre a taxa de aparecimento de folhas pode ter relação direta com a taxa de aparecimento de perfilhos, considerado que pastos de capim Tanzânia apresentam perfilhamento quase que exclusivo nas bases das suas plantas. O resultado mostrado na Figura 2 concorda os relatados nas revisões realizadas por WILMAN e WRIGHT (1983), WHITEHEAD (1995) e CRUZ e BOVAL (1999). Essas revisões mostraram que maiores quantidades de $\mathrm{N}$ aplicadas ao solo de pastagens determinam aumento da densidade populacional de perfilhos tanto em gramíneas de clima temperado como nas gramíneas de clima tropical. Resultado semelhante ao verificado no presente experimento foi obtido no experimento realizado por CANTO (2003). 
HOESCHL, A.R. et al. Produção de forragem...

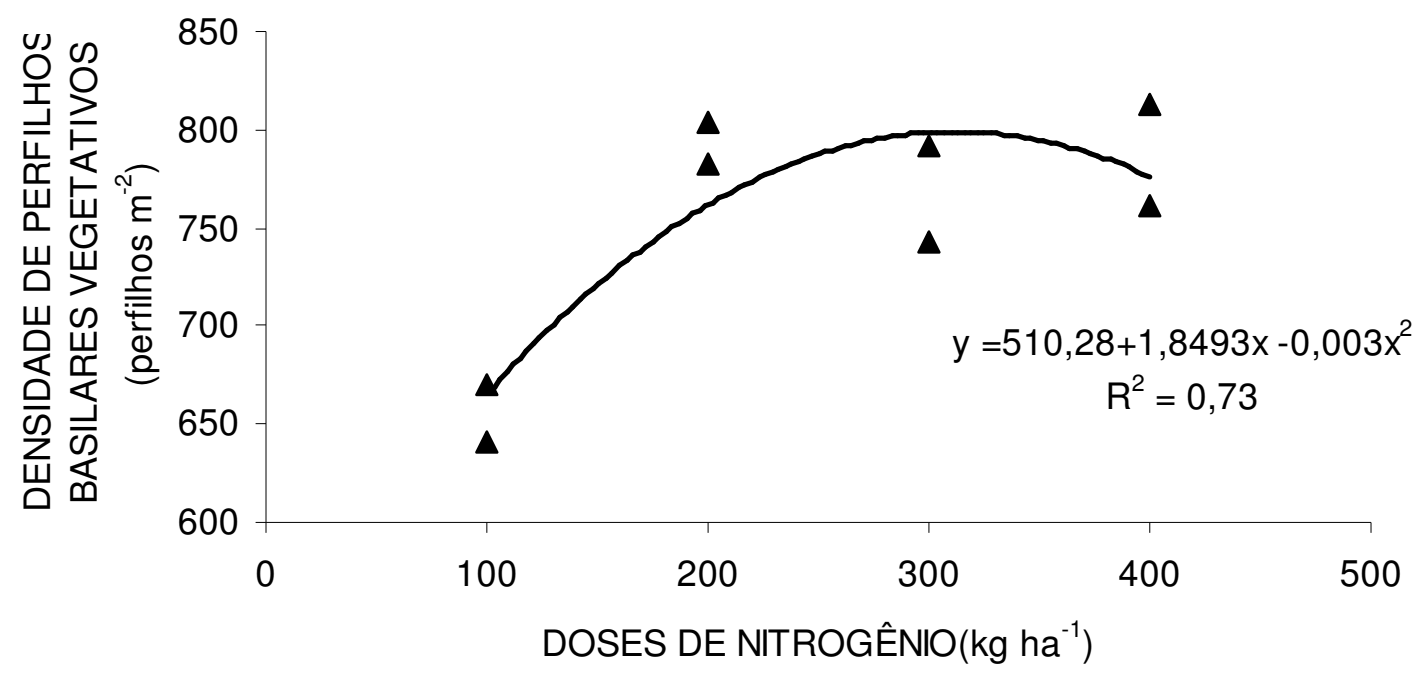

FIGURA 2 - Densidade populacional de perfilhos basilares vegetativos em pastos de capim Tanzânia adubados com diferentes doses de nitrogênio - Astorga, PR, 2002.

A relação das doses de $\mathrm{N}$ com a densidade populacional dos perfilhos aéreos vegetativos está na Figura 3. A relação linear positiva foi a que apresentou o melhor ajuste entre o número de perfilhos aéreos vegetativos e doses de $\mathrm{N}$. As médias de densidade populacional de perfilhos aéreos vegetativos foram 43 , 59,75 e de 91 perfilhos $\mathrm{m}^{-2}$ para os tratamentos 100 , 200,300 e $400 \mathrm{~kg} \mathrm{ha}^{-1}$ de N respectivamente. O aumento linear da densidade populacional de perfilhos aéreos vegetativos pode ter sido devido ao manejo utilizado na área experimental, que determinou alturas médias pouco mais altas nas doses mais elevadas de $\mathrm{N}$ durante o período experimental. Isso pode ter determinado a formação de maior quantidade de perfilhos aéreos a partir de colmos com entrenós alongados que foram desfolhados. Contudo, os mecanismos que determinam a formação de perfilhos aéreos em pastagens de capim Tanzânia ainda são desconhecidos.

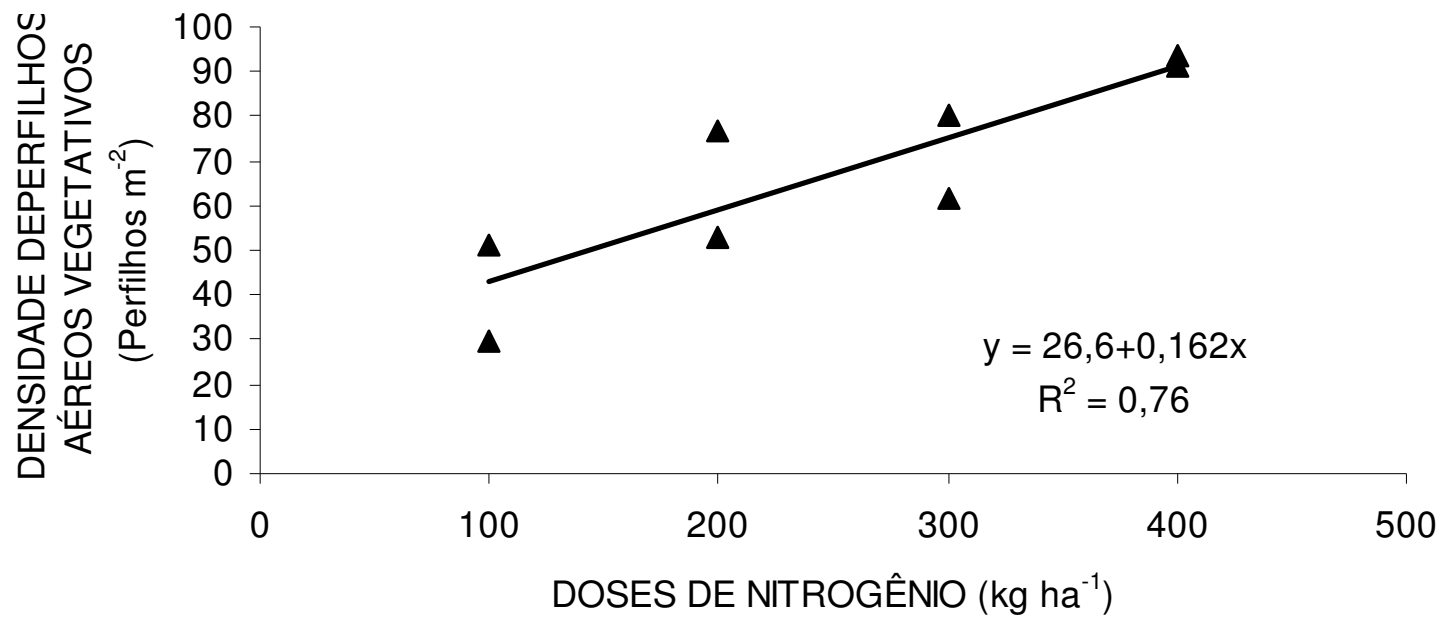

FIGURA 3 - Densidade populacional de perfilhos aéreos vegetativos em pastos de capim Tanzânia adubados com diferentes doses de nitrogênio - Astorga, PR, 2002. 
A taxa de acúmulo de MS apresentou resposta linear positiva $(P<0,0112)$ à medida que a quantidade de $\mathrm{N}$ aplicada na pastagem aumentou (Figura 4). Segundo a equação de regressão da Figura 4 as taxas de acúmulo de MS para as doses de $\mathrm{N}$ de 100,200,300 e de $400 \mathrm{~kg} \mathrm{ha}^{-1}$ foram, 150, 189, 203 e de $259 \mathrm{~kg}$ de MS ha ${ }^{-1}$ dia $^{-1}$ respectivamente.

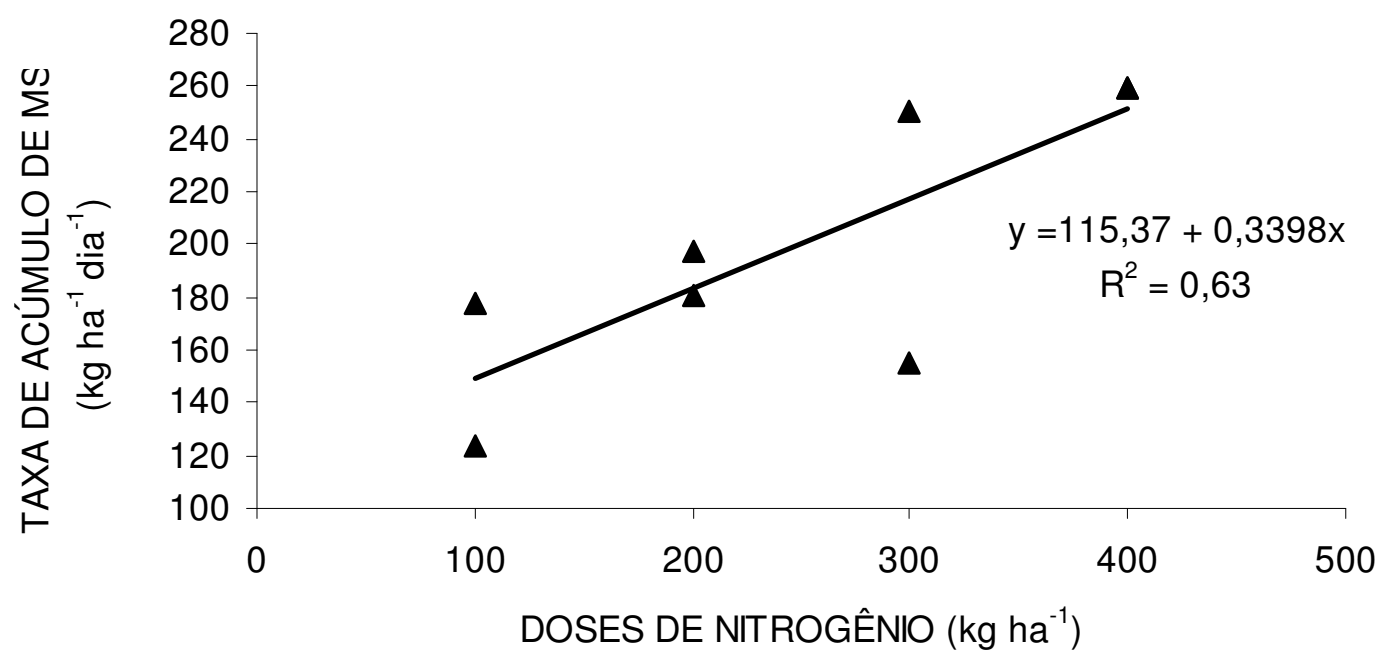

FIGURA 4 - Taxa de acúmulo de massa seca em pastos de capim Tanzânia adubados com diferentes doses de nitrogênio - Astorga, PR, 2002.

Os fatores que explicam as maiores taxas de acúmulo de MS em pastos que receberam maiores quantidades de $\mathrm{N}$ estão relacionadas com o aumento do índice de área foliar, maior taxa fotossintética por unidade de área foliar e por unidade de área de solo e, ainda, ao aumento da densidade populacional de perfilhos. Todos esses fatores interagem e devem ter atuado conjuntamente, determinando o comportamento mostrado na Figura 4. Com relação à densidade populacional de perfilhos vegetativos, o comportamento dessa variável está demonstrado na Figura 2. Segundo GASTAL e BÉLANGER (1993), a adubação nitrogenada aumenta a produção de forragem das pastagens devido, principalmente, à maior rapidez de desenvolvimento da área foliar e aumento da taxa de interceptação de luz pelo dossel.

Pode ser observado, na Figura 5, o aumento linear $(\mathrm{P}<0,03)$ da produção de forragem à medida que a quantidade de $\mathrm{N}$ aplicada na pastagem aumentou. Os valores obtidos de produção de forragem para as doses de 100, 200, 300 e $400 \mathrm{~kg} \mathrm{ha}^{-1}$ de N, foram de 19.120, $26.110,27.480$ e $33.540 \mathrm{~kg} \mathrm{ha}^{-1}$ de MS, respectivamente.

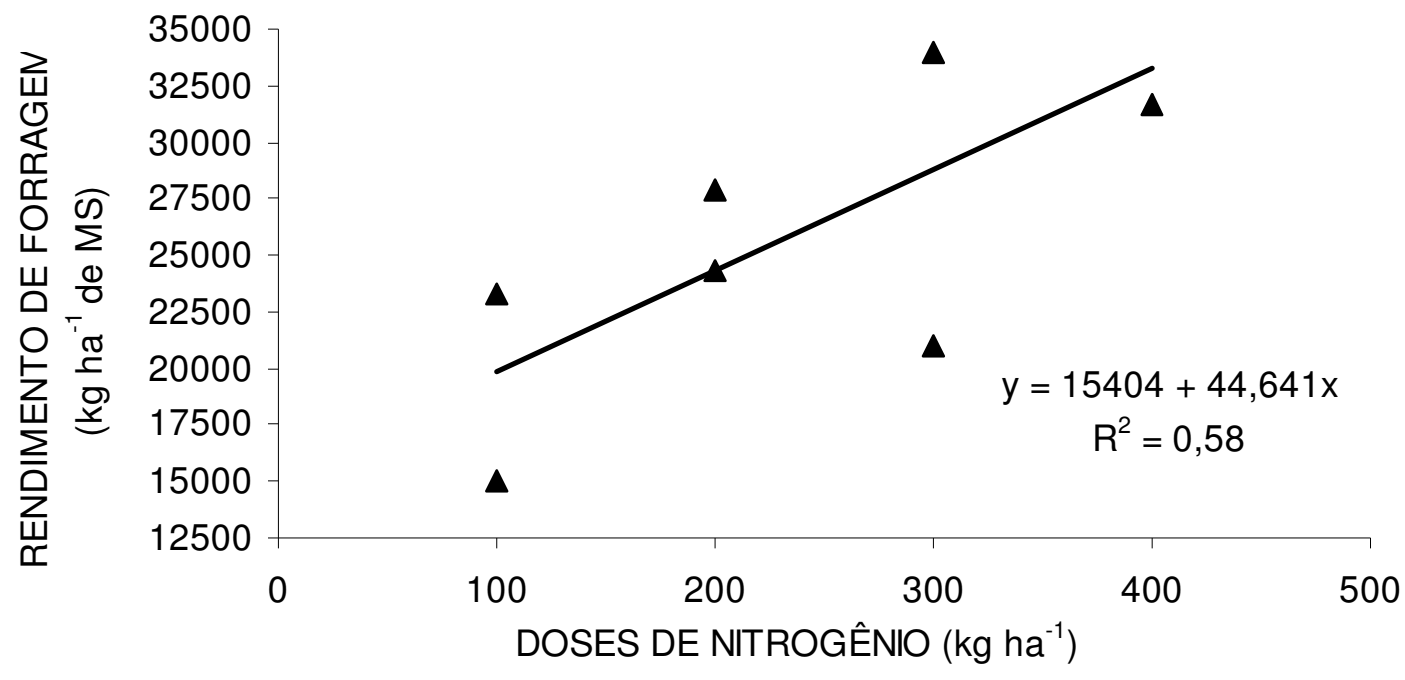

FIGURA 5 - Produção de forragem em pastos de capim Tanzânia adubados com diferentes doses de nitrogênio - Astorga, PR, 2002. 
As taxas de acúmulo de MS ao longo do experimento foram elevadas, e foram influenciadas pelas condições de alta fertilidade do solo da área experimental. Muitos experimentos no Brasil conduzidos em pastagens de Panicum maximum revelaram a significativa resposta à aplicação de $\mathrm{N}$ dessa espécie de gramínea tropical (CORSI e SANTOS, 1995). Os valores observados na Figura 5 são superiores ao verificados no experimento de pastejo realizado por CANTO (2003). Porém, deve ser ressaltado que esse último experimento de pastejo foi iniciado no mês de dezembro, posteriormente, a este experimento de pastejo. Os resultados de produção de forragem se assemelham aos verificados por LUGÃO (2001) com Panicum maximum (Acesso BRA-006998) sob lotação intermitente no Município de Paranavaí, localizado também na região Noroeste do Paraná. As doses de N de zero, 150, 300 e $450 \mathrm{~kg}$ ha $^{-1}$ no estudo de pastejo de LUGÃO (2001) determinaram, respectivamente, produções de forragem de $5.280,15.980,22.880$ e $31.020 \mathrm{~kg} \mathrm{ha}^{-1}$ de MS.

\section{CONCLUSÕES}

$\mathrm{O}$ aumento da dose de $\mathrm{N}$ determina aumento na massa individual de perfilhos e na densidade populacional de perfilhos basilares em estádio vegetativo.

A produção de forragem é aumentada de modo considerável com o aumento da dose de nitrogênio.

\section{REFERÊNCIAS}

1. BOGDAN, A.V. Tropical Pasture and Fodder Plants. London: Longman, 1977. $475 \mathrm{p}$.

2. CAMPBELL, A.G. Grazed pastures parameters; I. Pasture dry-matter production and availability in a stocking rate and grazing management experiment with dairy cows. Journal of Agricultural Science, Cambridge, n. 67: p. 211-216, 1966

3. CANTO, M.W.; CECATO, U.; ALMEIDA JÚNIOR, J.; JOBIM, C.C.; AGULHON, R.A.; GAI, V.F.; HOESCHL, A.R.; QUEIROZ, M.F.S. Produção animal no inverno em capim Tanzânia diferido no outono e manejado em diferentes alturas de pasto. Revista Brasileira de Zootecnia, Viçosa, v. 31, n. 4, p. 1624-1633, 2002.

4. CANTO, M.W. Dinâmica de crescimento e produção animal em capim Tanzânia adubado com doses de nitrogênio. Curitiba, 2003. 194 f. Tese (Doutorado em Agronomia, Produção Vegetal) - Setor de Ciências Agrárias, Universidade Federal do Paraná.

5. CORSI, M.; SANTOS, P.M. Potencial de produção do Panicum maximum. In: SIMPÓSIO SOBRE MANEJO DA PASTAGEM, 12., 1995, Piracicaba. Anais. Piracicaba: Fundação de Estudos Agrários Luiz de Queiroz, 1995. p. 275-303.

6. CRUZ, P.; BOVAL, M. Effect of nitrogen on some morphogenetical traits of temperate and tropical perennial forage grasses. In: INTERNATIONAL SYMPOSIUM “GRASSLAND ECOPHYSIOLOGYAND GRAZING ECOLOGY”, 1999, Curitiba. Proceedings. Curitiba: Universidade Federal do Paraná, 1999. p. 134-150.

7. EMBRAPA. Sistema brasileiro de classificação de solos. Brasília: Embrapa-SPI; Rio de Janeiro: Embrapa Solos, 1999. 412 p.

8. GASTAL, F.; BELANGER, G. The effects of nitrogen and growing season on photosynthesis of field grow tall fescue canopies. Annals of Botany, London, v. 72, p. 401-408, 1993.

9. GRASSLAND CONGRESS, 10., 1970, Queensland. Proceedings. Surfers Paradise: University of Queensland Press, 1970. p. 414-416.

10. HODGSON, J. The significance of sward characteristics in the management of temperate sown pastures. In: INTERNATIONAL GRASSLAND CONGRESS, 15., 1985, Kyoto. Proceedings. s.l.: s.ed., 1985. p. 63-66.

11. HODGSON, J. Grazing management - science into practice. Essex: Longman Scientific \& Technical, 1990. $203 \mathrm{p}$.

12. HOESCHL, A.R. Ganho de peso de novilhos nelore em uma pastagem de capim Tanzânia (Panicum maximum Jacq.) manejada em diferentes alturas de pastagem. Maringá, 1999. 22 f. Monografia (Graduação em Zootecnia) - Departamento de Zootecnia, Universidade Estadual de Maringá.

13. HUMPHREYS, L.R. Tropical pasture utilization. Cambridge: Cambridge University Press, 1991. $206 \mathrm{p}$

14. LEMAIRE, G.; CHAPMAN, D. Tissue Flows in grazed Plant Communities. In: HODGSON, J.; ILLIUS, A.W. (Ed.) The Ecology and Management of Grazing Systems. Wallingford: CAB International, 1996. p. 3-36.

15. LUGÃO, S.M.B. Produção de forragem e desempenho animal em pastagens de Panicum maximum Jacq. (acesso BRA006998) adubadas com nitrogênio na Região Noroeste do Paraná. Jaboticabal, 2001. 151 f. Tese (Doutorado em Zootecnia, Produção Animal) - Setor de Ciências Agrárias, Universidade Estadual Paulista.

16. MAZZANTI, A.; LEMAIRE, G.; GASTAL, F. The effect of nitrogen fertilization upon the herbage production of tall fescue swards continuously grazed with sheep. 1. Herbage growth dynamics. Grass and Forage Science, Oxford, v. 49, n. 2, p. 111-120, 1994.

17. MOTT, G. O., LUCAS, H. L. The design, conduct and interpretation of grazing trials on cultivated and improved pastures. In: INTERNATIONAL GRASSLAND CONGRESS, 6, 1952, Pennsylvania. Proceedings. Pennsylvania: State College Press, 1952. p. $1380-1385$

18. MOTT, G.O.; QUINN, L.R.; BISSCHOFF, W.V.A. The retention of nitrogen in a soil-plant-animal system in guinea grass (Panicum maximum) pastures in Brazil. In: INTERNATIONAL GRASSLANDS CONGRESS, 10., 1970. Proceedings. Surfers Paradise: University of Quensland Press, 1970. p. 414-416.

19. WHITEHEAD, D.C. Grassland Nitrogen. Wallingford: CAB INTERNATIONAL. 1995. 397 p.

20. WILMAN, D.; WRIGHT, P.T. Some effects of applied nitrogen on the growth and chemical composition of temperate grasses. Herbage Abstracts, Hurley, v. 53, n. 8, p. 387-393, 1983. 